\title{
Different Radiation Tolerances of Ultrafine-Grained Zirconia-Magnesia Composite Ceramics with Different Grain Sizes
}

\author{
Wenjing Qin ${ }^{1,2,+}$, Mengqing Hong ${ }^{1,3,+}$, Yongqiang Wang ${ }^{4} \oplus$, Jun Tang ${ }^{1}$, Guangxu Cai ${ }^{1}$, \\ Ran Yin ${ }^{1}$, Xuefeng Ruan ${ }^{5}$, Bing Yang ${ }^{5}$, Changzhong Jiang ${ }^{1}$ and Feng Ren ${ }^{1, *}$ \\ 1 School of Physics and Technology, Center for Ion Beam Application, Hubei Nuclear Solid Physics Key \\ Laboratory and MOE Key Laboratory of Artificial Micro- and Nano-Structures, Wuhan University, \\ Wuhan 430072, China \\ 2 School of Physics and Electronics, Key Laboratory of Low Dimensional Quantum Structures and Quantum \\ Control, Hunan Normal University, Changsha 410081, China \\ 3 The Institute of Technological Sciences, Wuhan University, Wuhan 430072, China \\ 4 Materials Science and Technology Division, Los Alamos National Laboratory, Los Alamos, NM 87545, USA \\ 5 School of Power and Mechanical Engineering, Wuhan University, Wuhan 430072, China \\ * Correspondence: fren@whu.edu.cn \\ + The authors are co-first authors.
}

Received: 1 August 2019; Accepted: 19 August 2019; Published: 21 August 2019

check for updates

\begin{abstract}
Developing high-radiation-tolerant inert matrix fuel (IMF) with a long lifetime is important for advanced fission nuclear systems. In this work, we combined zirconia $\left(\mathrm{ZrO}_{2}\right)$ with magnesia $(\mathrm{MgO})$ to form ultrafine-grained $\mathrm{ZrO}_{2}-\mathrm{MgO}$ composite ceramics. On the one hand, the formation of phase interfaces can stabilize the structure of $\mathrm{ZrO}_{2}$ as well as inhibiting excessive coarsening of grains. On the other hand, the grain refinement of the composite ceramics can increase the defect sinks. Two kinds of composite ceramics with different grain sizes were prepared by spark plasma sintering (SPS), and their radiation damage behaviors were evaluated by helium $(\mathrm{He})$ and xenon $(\mathrm{Xe})$ ion irradiation. It was found that these dual-phase composite ceramics had better radiation tolerance than the pure yttria-stabilized $\mathrm{ZrO}_{2}$ (YSZ) and $\mathrm{MgO}$. Regarding $\mathrm{He}^{+}$ion irradiation with low displacement damage, the $\mathrm{ZrO}_{2}-\mathrm{MgO}$ composite ceramic with smaller grain size had a better ability to manage He bubbles than the composite ceramic with larger grain size. However, the $\mathrm{ZrO}_{2}-\mathrm{MgO}$ composite ceramic with a larger grain size could withstand higher displacement damage in the phase transformation under heavy ion irradiation. Therefore, the balance in managing He bubbles and phase stability should be considered in choosing suitable grain sizes.
\end{abstract}

Keywords: $\mathrm{ZrO}_{2}-\mathrm{MgO}$; ultrafine grain; irradiation; He bubble; phase transformation

\section{Introduction}

Ceramics with high radiation tolerance are often used for radioactive waste management as inert matrix fuel (IMF) and cladding materials for fission reactors [1]. Zirconia $\left(\mathrm{ZrO}_{2}\right)$ is considered to be a promising material for IMF to burn minor actinides, plutonium and to immobilize high-level nuclear waste because of its excellent physical and chemical stability, including thermal and radiation stability and low neutron capture cross-section [2]. To enhance the radiation tolerance of $\mathrm{ZrO}_{2}$ under various energetic particles' (He, Xe, Cs, and so on) irradiation environments, one of the effective methods is to reduce its grain size. Nanostructured materials contain abundant grain boundaries (GBs) or phase interfaces, which can effectively act as "sinks" to attract, absorb, and annihilate defects [3,4]. Refining the grain size to increase the density of GBs is a widely used method to improve the radiation tolerance 
performance of materials. Compared to bulk nickel (Ni), nanocrystalline $\mathrm{Ni}$ with an average grain size of $55 \mathrm{~nm}$ can significantly reduce the density and size of defect clusters induced by irradiation [5]. Nanocrystalline $\mathrm{MgGa}_{2} \mathrm{O}_{4}$ with an $\sim 8 \mathrm{~nm}$ size can tolerate 96 displacements per atom (dpa) without any signs of amorphizing, while the large grain $(\sim 10 \mu \mathrm{m})$ counterpart begins to amorphize just at $12 \mathrm{dpa}$ [6]. The intrinsic reason for the radiation tolerance of GB-reinforced materials is that the GBs have a "loading-unloading" effect, making the radiation-induced damage "self-healing". A low energy barrier or even barrier-free region is formed around interstitial atoms when the interstitial atoms are loaded in or near the GBs, which promotes the annihilation of vacancy $[7,8]$.

However, it was also found that a small grain size did not always indicate high radiation tolerance. Lu et al. found that monoclinic $\mathrm{ZrO}_{2}$ with a grain size less than $40-50 \mathrm{~nm}$ was much easier to amorphize than the bulk component under swift heavy ion irradiation [9]. Radiation tolerance performance of the nanostructured material is size-dependent, according to the theory of kinetics and thermodynamics [10]. The ideal grain size for nanocrystals with "self-healing" behavior may be a delicate balance between the excess free energy from GB, the free energy of phase transition and defect formation, and the healing kinetics [11]. Since there are no available data for the ideal grain size of nanostructured $\mathrm{ZrO}_{2}$, it is worthy of further exploration for the purpose of avoiding these problems.

Furthermore, most nanocrystalline grains will undergo rapid coarsening under high temperature or ion irradiation, decreasing the density of GBs and effectively weakening the sink of GBs [12,13]. Because multiphase composition can increase the coupling diffusion distance of the same component grain, it can reduce the driving forces of grain growth and improve the stability of the GBs [14]. Magnesia (MgO), with a low neutron capture cross-section, high thermal conductivity, and high electrical conductivity, is regarded as a promising contender in the nuclear energy field [15]. In this work, to improve the stability of $\mathrm{ZrO}_{2}$, we added $\mathrm{MgO}$ to the $\mathrm{ZrO}_{2}$ and prepared ultrafine-grained $\mathrm{ZrO}_{2}-\mathrm{MgO}$ dual-phase composite ceramics with two different grain sizes by spark plasma sintering (SPS). The evolution behavior of defects and the mechanisms of radiation tolerance in these dual-phase composite ceramics were investigated by irradiation of light helium $(\mathrm{He})$ ion and heavy xenon $(\mathrm{Xe})$ ion, respectively.

\section{Materials and Methods}

\subsection{Material Preparation}

$\mathrm{ZrO}_{2}-\mathrm{MgO}$ composite ceramics were prepared by mixing monoclinic $\mathrm{ZrO}_{2}$ powders (99.99\%) and cubic $\mathrm{MgO}$ powders (99.99\%) with a volume ratio of 1:1, and sintered by using SPS. The average grain sizes of the $\mathrm{ZrO}_{2}$ and $\mathrm{MgO}$ powders were $\sim 50 \mathrm{~nm}$, and they were purchased from Aladdin Reagents Co. Ltd (Shanghai, China); the relevant grain orientations can be seen in Supplementary Figure S1. To obtain different grain sizes and control the excessive growth of the grains, the mixing $\mathrm{ZrO}_{2}-\mathrm{MgO}$ powders were sintered at $1373 \mathrm{~K}$ and $1623 \mathrm{~K}$ with the same pressure $(80 \mathrm{MPa})$, respectively. In addition, the individual pure $\mathrm{ZrO}_{2}$ and $\mathrm{MgO}$ ceramics were used as comparison samples. Large-grained $\mathrm{MgO}$ ceramics with dozens of microns were sintered at $1673 \mathrm{~K}$ with $100 \mathrm{MPa}$ pressure. The cubic $\{110\}$-oriented, single-crystal, yttria-stabilized $\mathrm{ZrO}_{2}$ (YSZ) was supplied by Kejing Materials Company in Hefei, China. All the sintered samples were annealed in vacuum at $1073 \mathrm{~K}$ for $4 \mathrm{~h}$ to remove infiltrated carbon.

\subsection{Light $\mathrm{He}^{+}$Ion Irradiation}

To explore the effect of grain boundary on the $\mathrm{He}$ atom behavior, the ultrafine-grained $\mathrm{ZrO}_{2}-\mathrm{MgO}$ composites with different grain sizes, YSZ, and $\mathrm{MgO}$ were irradiated at $773 \mathrm{~K}$ by $50 \mathrm{keV} \mathrm{He}^{+}$ions to fluences of $3 \times 10^{16}, 5 \times 10^{16}$, and $1 \times 10^{17} \mathrm{ions} / \mathrm{cm}^{2}$, respectively. The ion flux was controlled at about $1.8 \times 10^{13}$ ions $/ \mathrm{cm}^{2} \mathrm{~s}$. The $\mathrm{He}^{+}$ion irradiation experiments were performed using the $200 \mathrm{keV}$ ion implanter (LC22-100-01, Beijing Zhongkexin Electronics Equipment Co., Ltd, Beijing, China) at the Center for Ion Beam Application, Wuhan University. The displacement per atom (dpa) and He concentration of the samples irradiated to a fluence of $1 \times 10^{16} \mathrm{ions} / \mathrm{cm}^{2}$ were calculated by SRIM-2013 with a "Quick Kinchin-Pease" mode [16], where the threshold displacement energies ( $\left.\mathrm{E}_{\mathrm{d}}\right)$ of $\mathrm{Zr}, \mathrm{Mg}$, 
and $\mathrm{O}$ atoms were all set to $40 \mathrm{eV}$, and the theoretical density values of $\mathrm{ZrO}_{2}-\mathrm{MgO}, \mathrm{YSZ}$, and $\mathrm{MgO}$ $\left(4.63,6.10\right.$, and $\left.3.58 \mathrm{~g} / \mathrm{cm}^{3}\right)$ were used, respectively [17-19]. The calculation results of the $\mathrm{ZrO}_{2}-\mathrm{MgO}$ composite are shown in Figure 1a. The maximum dpa was about 0.21 at the depth of around $228 \mathrm{~nm}$, and the peak He concentration was about 0.72 at. \% at the depth of around $282 \mathrm{~nm}$. The relevant calculation results of the other two comparison samples are shown in Table S1.
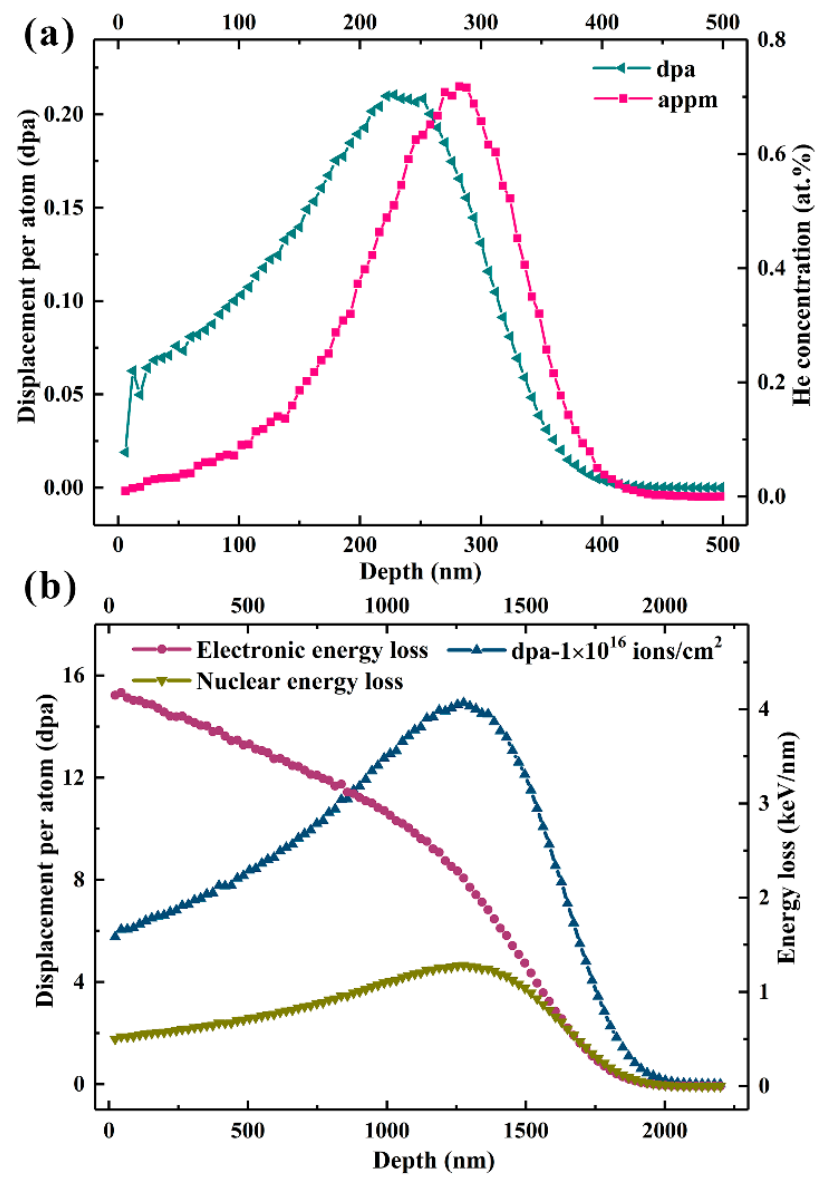

Figure 1. The SRIM-2013 results of (a) displacement per atom (dpa) and He concentration in the $\mathrm{ZrO}_{2}-\mathrm{MgO}$ composite irradiated by $50 \mathrm{keV} \mathrm{He}{ }^{+}$ions to a fluence of $1 \times 10^{16} \mathrm{ions} / \mathrm{cm}^{2}$, and (b) displacement per atom, and electronic and nuclear energy loss in the $\mathrm{ZrO}_{2}-\mathrm{MgO}$ composite irradiated by $6.4 \mathrm{MeV} \mathrm{Xe} \mathrm{e}^{23+}$ ions to a fluence of $1 \times 10^{16}$ ions $/ \mathrm{cm}^{2}$.

\subsection{Heavy $\mathrm{Xe}^{23+}$ Ion Irradiation}

To further investigate the influence of cascade damage on samples, $6.4 \mathrm{MeV} \mathrm{Xe}^{23+}$ ions were used to irradiate the different-grain-sized $\mathrm{ZrO}_{2}-\mathrm{MgO}$ composites, $\mathrm{YSZ}$, and $\mathrm{MgO}$ at room temperature (RT) on the $320 \mathrm{kV}$ platform for multi-disciplinary research with highly charged ions at the Institute of Modern Physics, Chinese Academy of Sciences (CAS). The fluences were $5 \times 10^{15}, 1 \times 10^{16}$, and $3 \times 10^{16}$ ions $/ \mathrm{cm}^{2}$, respectively. The results of SRIM calculation are shown in Figure $1 \mathrm{~b}$, which were also simulated by a "Quick Kinchin-Pease" mode. For the $\mathrm{ZrO}_{2}-\mathrm{MgO}$ composite, the maximum displacement per atom reached up to $15 \mathrm{dpa}$ at the depth of around $1.27 \mu \mathrm{m}$ when the fluence was $1 \times 10^{16}$ ions $/ \mathrm{cm}^{2}$. Both electronic energy loss and nuclear energy loss contributed to the irradiation damage, because they were in the same order of magnitude [20].

\subsection{Characterization Method}

The changes of microstructures were observed by transmission electron microscopy (TEM, JEOL JEM-2010 (HT), JEOL, Ltd., Tokyo, Japan). Cross-sectional TEM samples were prepared using a 
conventional precision ion polishing system (Gatan 691, Gatan, Inc., Pleasanton, CA, USA). Raman scattering spectra were characterized by a commercial Raman microscope (HR800, Horiba, Ltd., Longjumeau, France) using an $\mathrm{Ar}^{+}$ion laser excitation source $(\lambda=488 \mathrm{~nm})$. Crystalline structures of the pristine and irradiated samples were identified by grazing incidence $X$-ray diffraction (GIXRD, Rigaku, Japan) on a SmartLab $9 \mathrm{~kW}$ with $\mathrm{Cu} K \alpha$ radiation. The X-ray penetration depth in the $\mathrm{ZrO}_{2}-\mathrm{MgO}$ composites versus grazing incidence angle $(\alpha)$ were estimated geometrically, critical angle $\left(\alpha_{c}\right)$, and total external reflection theory [21,22], as shown in Figure S2. Considering the damage depth induced by $50 \mathrm{keV} \mathrm{He}^{+}$ions, $0.5^{\circ}$ grazing incidence angle was chosen.

\section{Results and Discussion}

\subsection{Properties of Pristine Samples}

Figure $2 \mathrm{a}, \mathrm{b}$ show the bright-field TEM images of the $\mathrm{ZrO}_{2}-\mathrm{MgO}$ composite ceramics sintered at $1373 \mathrm{~K}$ and $1673 \mathrm{~K}$, respectively. The white grain is $\mathrm{MgO}$ and the black is $\mathrm{ZrO}_{2}$, judged by selected area electron diffraction (SAED). The average grain size of the $\mathrm{ZrO}_{2}-\mathrm{MgO}$ composite sintered at $1373 \mathrm{~K}$ was $110.2 \pm 45.1 \mathrm{~nm}$, while that of the $\mathrm{ZrO}_{2}-\mathrm{MgO}$ composite sintered at $1673 \mathrm{~K}$ was $349.0 \pm 76.2 \mathrm{~nm}$, as shown in Figure 2c. For convenience of marking, they are labeled as SGs and LGs according to the grain size, respectively. Figure $2 \mathrm{~d}$ shows the corresponding crystalline structures. Clearly, the $\mathrm{ZrO}_{2}$ in the SGs and LGs was a mixture of monoclinic and tetragonal phase, but the proportion of the tetragonal phase was different. The Gravice and Nicholson method was used to estimate the proportion of tetragonal phase in the two mixed phases of $\mathrm{ZrO}_{2}$ [23]. The relevant expression is as follows:

$$
C_{t}=\frac{I_{t}(101)}{I_{m}(111)+I_{t}(101)+I_{m}(-111)}
$$

where $I$ refers to the intensity of diffraction peak obtained from the GIXRD. The proportions of tetragonal phase in the SGs and LGs were $15.1 \%$ and $24.7 \%$, respectively. Therefore, there were two different aspects between the SGs and LGs: (i) the average grain size; (ii) the proportion of the tetragonal phase.
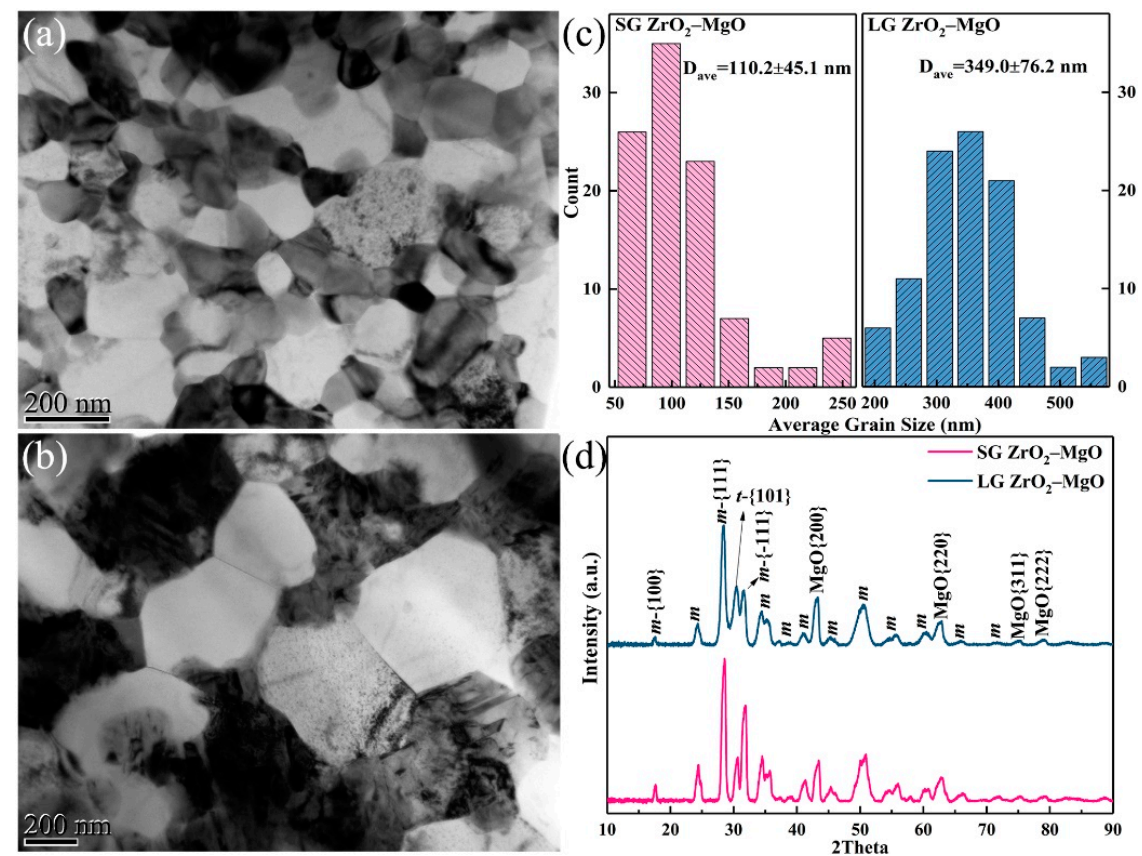

Figure 2. Bright-field transmission electron microscope (TEM) images of the pristine small-grain (SG) (a) and large-grain (LG) (b) $\mathrm{ZrO}_{2}-\mathrm{MgO}$ composite ceramics sintered by spark plasma sintering (SPS); statistical average grain size of $\mathrm{SG}$ and $\mathrm{LG} \mathrm{ZrO}_{2}-\mathrm{MgO}$ (c), and their crystalline structures measured by grazing incidence $X$-ray diffraction (GIXRD) (d). 


\subsection{Microstructure Evolution under $\mathrm{He}^{+}$Ion Irradiation}

Figure 3 shows the cross-sectional TEM images of SGs, LGs, MgO, and YSZ irradiated at $773 \mathrm{~K}$ by $50 \mathrm{keV} \mathrm{He}^{+}$ions to fluences of $3 \times 10^{16}, 5 \times 10^{16}$, and $1 \times 10^{17}$ ions $/ \mathrm{cm}^{2}$, respectively. These images were obtained from the regions of peak damage depth. At the lowest fluence, it is obvious that there were many large cracks in the YSZ (Figure 3d). Large numbers of He bubble chains were observed in the $\mathrm{MgO}$ (Figure 3c), and large, ribbon-like bubbles appeared in the LGs (Figure 3b), while only very small bubbles were found in the SGs (Figure 3a). Note that the ribbon-like He bubbles in the LGs only existed in the grains of $\mathrm{ZrO}_{2}$. At the same irradiation condition, the distribution of He bubbles in the $\mathrm{MgO}$ and $\mathrm{ZrO}_{2}$ (or YSZ) was obviously different; the distribution range with obvious He bubbles in the $\mathrm{MgO}$ was larger than that in the YSZ. This was because the migration barrier of the interstitial atoms in the $\mathrm{MgO}$ was much lower than that in the $\mathrm{ZrO}_{2}$, which resulted in the diffusion of the interstitial atoms in the $\mathrm{MgO}$ to a deeper position, thereby also leading to a wide distribution of residual vacancies [24]. In addition, vacancies in the $\mathrm{MgO}$ were immobile at this current irradiation temperature (773 K), and they begin to mobilize only when the temperature was higher than $873 \mathrm{~K}$ [19]. Thus, at the low fluence, it is possible that the implanted He atoms were trapped by these isolated vacancies with wide distribution and stabilized the vacancies formed there, which further reduced the accumulation of He bubbles [25]. This led to the absence of the large, ribbon-like He bubbles in the grains of $\mathrm{MgO}$. With the increase of fluence to $5 \times 10^{16}$ ions $/ \mathrm{cm}^{2}$, cracks were also formed in the LGs and $\mathrm{MgO}$. However, no cracks were found in the SGs, although relatively large-sized He bubbles were observed. When the fluence was further increased to $1 \times 10^{17}$ ions $/ \mathrm{cm}^{2}$, small cracks appeared in the SGs, and the number and size of the cracks become greater in the LGs. Compared with the pure $\mathrm{MgO}$ and YSZ, the dual-phase composite ceramic had better radiation tolerance in managing He bubbles. Meanwhile, for the dual-phase composite ceramic, large He bubbles were more likely to form in the $\mathrm{ZrO}_{2}$ grains, and the SGs with relatively smaller grain size had better management of He bubbles than the LGs.

To further understand the lattice changes induced by $\mathrm{He}^{+}$ion irradiation, the GIXRD patterns of the pristine SGs (Figure $4 \mathrm{a}$ ) and LGs (Figure $4 \mathrm{~b}$ ) irradiated to fluences of $3 \times 10^{16}, 5 \times 10^{16}$, and $1 \times 10^{17}$ ions $/ \mathrm{cm}^{2}$ were measured and are shown in Figure 4. To facilitate observation, the diffraction patterns (angles $(2 \theta)$ between $26^{\circ}$ and $35^{\circ}$, which are the main peak positions of monoclinic and tetragonal phases) have been magnified. Clearly, no amorphization and phase transformation were found in the SGs and LGs after $\mathrm{He}^{+}$ion irradiation. Thus, the specific orientation corresponding to the diffraction peak can be referred to Figure $2 \mathrm{~d}$. With increase of the fluence, the intensities of the main diffraction peaks were gradually reduced and the peaks became broader. The deviations of all the diffraction peaks were very different with the increasing fluence.

Because there were large numbers of diffraction peaks in the $\mathrm{ZrO}_{2}-\mathrm{MgO}$ composite ceramic, to facilitate the analysis, three main representative peaks, $\{111\}_{m},\{101\}_{t}$, and $\{200\}_{M g O}$, were selected for comparison to study the influence of irradiation. The diffraction angle values of these three main peaks that varied with increase of the fluence are listed in Table 1, and the diffraction angle was measured by the full width at half maximum (FWHM) of the peak. The diffraction peaks $\{111\}_{m}$ of the irradiated SGs and LGs both shifted to a lower angle and the shifts were small relative to their pristine samples. The offset of LGs increased gradually with the increase of fluence, while the offset of SGs increased gradually and then decreased at a fluence of $1 \times 10^{17} \mathrm{ions} / \mathrm{cm}^{2}$. The variation tendency of the diffraction peaks $\{101\}_{t}$ and $\{200\}_{M g O}$ were similar to that of peak $\{111\}_{m}$ in the SGs. However, for the irradiated LGs, the variation of the peak $\{101\}_{t}$ and $\{200\}_{M g O}$ was very different from that of the peak $\{111\}_{m}$. The peak $\{101\}_{t}$ shifted to the right after irradiation and did not change with the increase of fluence, while the peak $\{200\}_{M g O}$ shifted first to the right and then to the left as the fluence increased. From the above analysis, it can be seen that the shift tendency of each peak under different damage conditions was different, which means that its ability to resist $\mathrm{He}^{+}$ion irradiation was different. Referring to Figure 3, it can be considered that the left-shift of the diffraction peak was produced due to the lattice swelling induced by He bubbles, while the subsequent right-shift of the peaks in SGs was mainly due 
to the stress relaxation induced by crack formation, as shown in the TEM image [26,27]. For the LGs, although the cracks formed under high He concentration, this did not affect the continued swelling of the monoclinic grains (peak $\{111\}_{m}$ ), which may have been due to the large grain size preventing the release of He in time. Stress relaxation occurred in the peaks $\{101\}_{t}$ and $\{200\}_{M g O}$, possibly because of the combination of the crack formation and thermal effects (long-time high temperature irradiation).
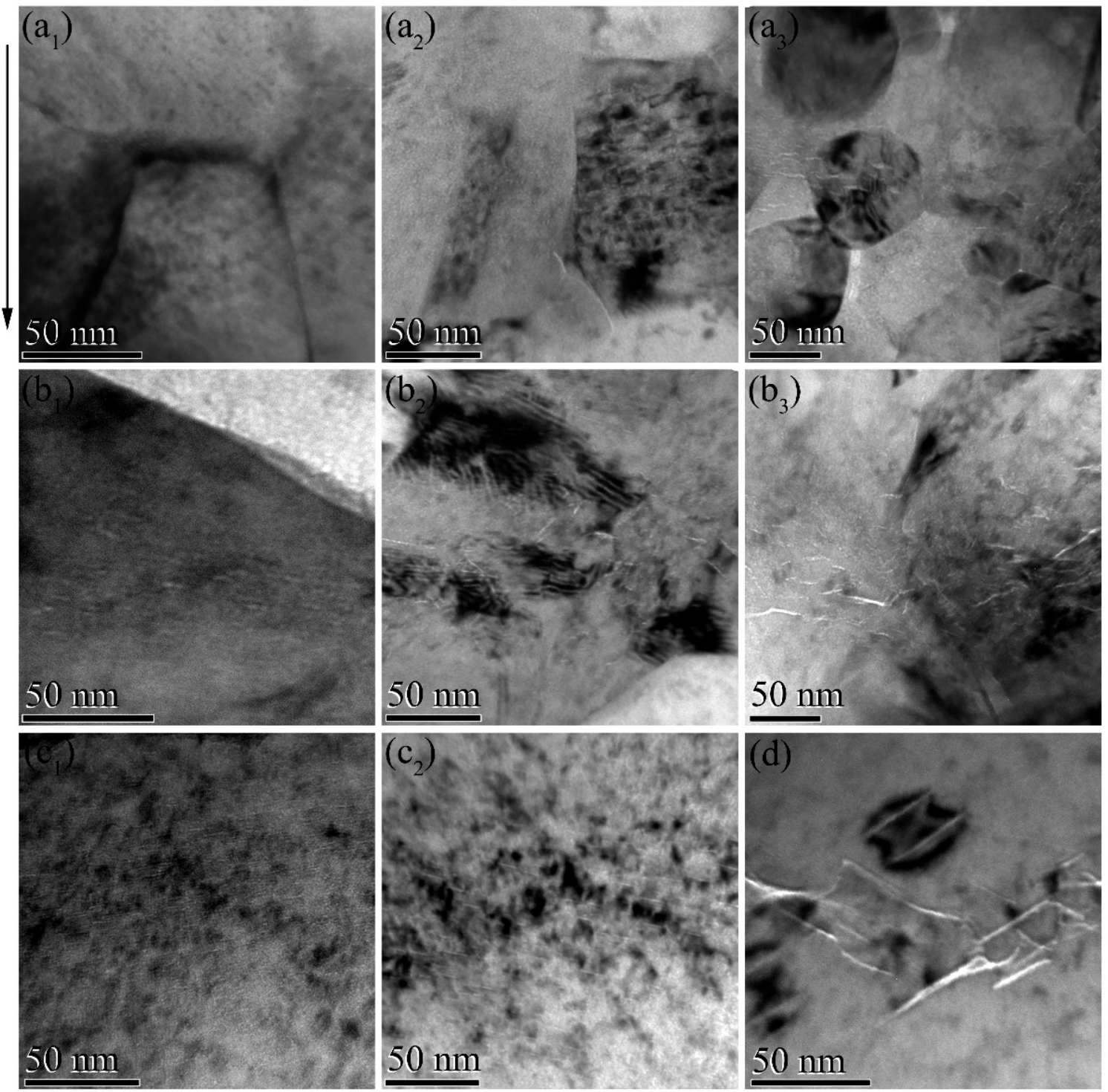

Figure 3. Cross-sectional TEM images of the SGs (a), LGs (b), $\mathrm{MgO}$ (c), and yttria-stabilized $\mathrm{ZrO}_{2}$ (YSZ) (d) irradiated at $773 \mathrm{~K}$ by $50 \mathrm{keV} \mathrm{He}{ }^{+}$ions to fluences of $3 \times 10^{16}\left(\mathbf{a}_{1}, \mathbf{b}_{1}, \mathbf{c}_{1}, \mathbf{d}\right), 5 \times 10^{16}\left(\mathbf{a}_{2}, \mathbf{b}_{2}, \mathbf{c}_{2}\right)$, and $1 \times 10^{17}\left(\mathbf{a}_{3}, \mathbf{b}_{3}\right)$ ions $/ \mathrm{cm}^{2}$, respectively. Black scale bars of different lengths all represent $50 \mathrm{~nm}$. The arrow indicates the direction of ion incidence in the images. 

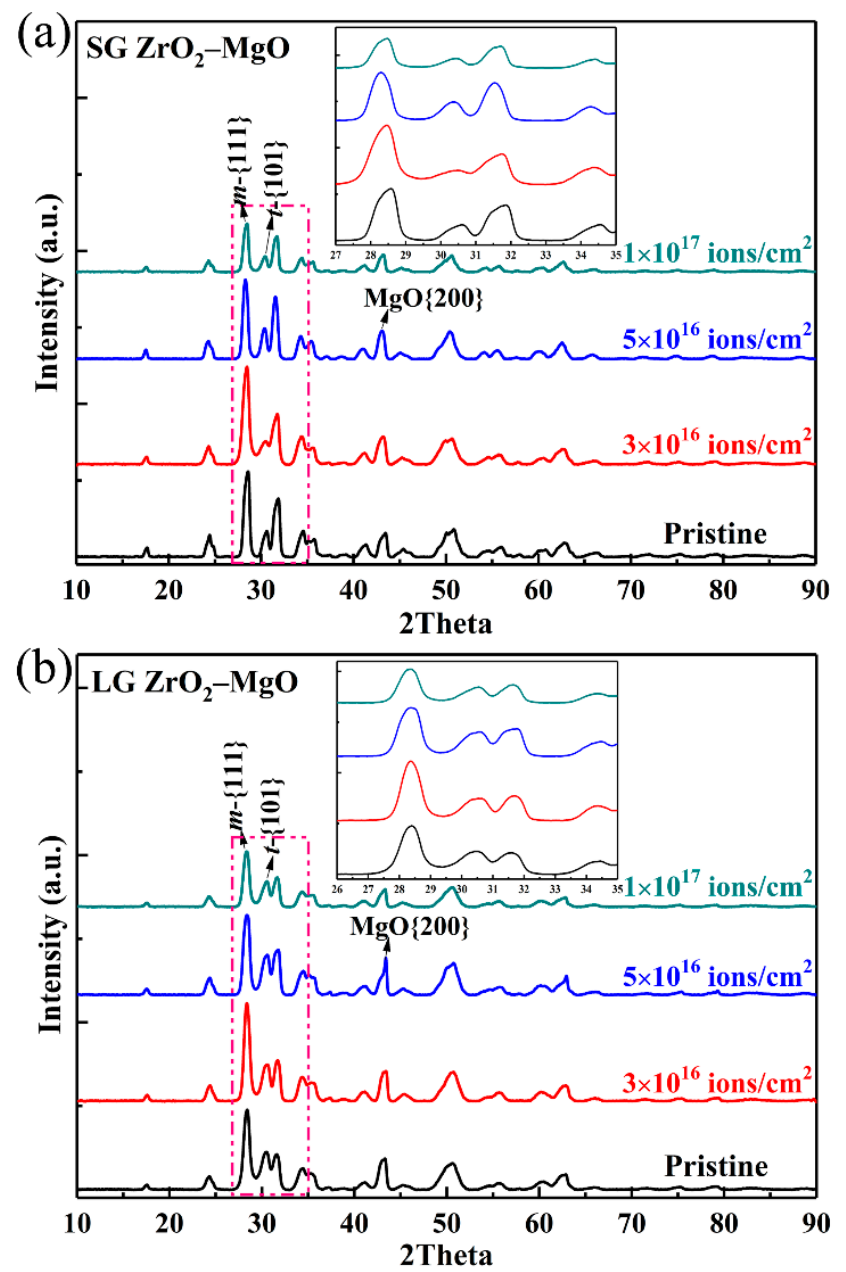

Figure 4. GIXRD patterns of the pristine SGs (a) and LGs (b) irradiated by $50 \mathrm{keV} \mathrm{He}$ ions to the fluences of $3 \times 10^{16}, 5 \times 10^{16}$, and $1 \times 10^{17}$ ions $/ \mathrm{cm}^{2}$ at $773 \mathrm{~K}$; the magnifications of diffraction peaks in the dashed frame are inserted.

Table 1. Diffraction angle $2 \theta\left(^{\circ}\right)$ values of the $\{111\}_{m},\{101\}_{t}$, and $\{200\}_{\mathrm{MgO}}$ peaks in the SG and LG samples at different irradiation fluences, obtained from GIXRD patterns. The variation values relative to the pristine peak are listed in parentheses.

\begin{tabular}{|c|c|c|c|c|}
\hline Sample & Pristine & $3 \times 10^{16}$ & $5 \times 10^{16}$ & $1 \times 10^{17}$ \\
\hline SGs $-\{111\}_{m}$ & 28.42 & $28.34(-0.08)$ & $28.28(-0.14)$ & $28.34(-0.08)$ \\
\hline LGs- $\{111\}_{m}$ & 28.40 & $28.36(-0.04)$ & $28.32(-0.08)$ & $28.30(-0.10)$ \\
\hline SGs- $\{101\}_{t}$ & 30.50 & $30.44(-0.06)$ & $30.34(-0.16)$ & $30.40(-0.10)$ \\
\hline LGs- $\{101\}_{t}$ & 30.40 & $30.46(+0.06)$ & $30.46(+0.06)$ & $30.46(+0.06)$ \\
\hline SGs- $\{200\}_{M g O}$ & 43.18 & $43.02(-0.16)$ & $43.00(-0.18)$ & $43.04(-0.14)$ \\
\hline LGs- $\{200\}_{\mathrm{MgO}}$ & 43.04 & $43.16(+0.12)$ & $43.10(+0.06)$ & $43.04(+0)$ \\
\hline
\end{tabular}

\subsection{Heavy $\mathrm{Xe}^{23+}$ Ion Irradiation}

Raman scattering is a powerful technique used to characterize the microstructural evolution after irradiation. Figure 5 shows the Raman spectra of the pristine SGs and LGs irradiated by $6.4 \mathrm{MeV} \mathrm{Xe}^{23+}$ ions to the fluences of $5 \times 10^{15}, 1 \times 10^{16}$, and $3 \times 10^{16}$ ions $/ \mathrm{cm}^{2}$, respectively. Group theory predicted 18 Raman active modes $\left(9 \mathrm{~A}_{\mathrm{g}}+9 \mathrm{~B}_{\mathrm{g}}\right)$ for the monoclinic $\mathrm{ZrO}_{2}, 6$ Raman active modes $\left(\mathrm{A}_{1 \mathrm{~g}}+2 \mathrm{~B}_{1 \mathrm{~g}}+3 \mathrm{E}_{\mathrm{g}}\right)$ for the tetragonal $\mathrm{ZrO}_{2}$, and only 1 Raman active mode for the cubic $\mathrm{ZrO}_{2}$, which appeared at around $600 \mathrm{~cm}^{-1}$ [28]. By comparing the Raman spectra of different phases of $\mathrm{ZrO}_{2}$ [29], it was found that the pristine SGs and LGs were mainly composed of the monoclinic phase, as well as the tetragonal phase 
of $\mathrm{ZrO}_{2}$. No Raman band of $\mathrm{MgO}$ was observed in this wavenumber range. Among the Raman bands of the pristine samples, only three bands represented the tetragonal phase, which have been marked in Figure 5, while the others corresponded to the monoclinic phase. Compared with the pristine SGs, the bands in the pristine LGs were shifted to lower wavenumbers, and the spectral peaks of some bands become less obvious, such as at around 186, 310,346, 503, 539, and $621 \mathrm{~cm}^{-1}$. Unexpectedly, huge spectral changes occurred in the irradiated SGs and LGs. The peak intensities of spectral bands sharply declined and decreased with the increase of the irradiation fluence. At the lowest fluence of $5 \times 10^{15}$ ions $/ \mathrm{cm}^{2}$ (corresponding to peak damage of $7.5 \mathrm{dpa}$ ), a new band at $710 \mathrm{~cm}^{-1}$ appeared in the LGs, and the other bands corresponding to the monoclinic and tetragonal phases still existed. However, in the SGs, many bands, such as at 148, 181, 224, 310, 336, 351, 506, 541,566, and $645 \mathrm{~cm}^{-1}$, all disappeared. The bands at 188 and $619 \mathrm{~cm}^{-1}$ were formed by the left-shift of the corresponding original bands. Meanwhile, two new bands appeared at 259 and $712 \mathrm{~cm}^{-1}$. The intensities of bands at 385 and $478 \mathrm{~cm}^{-1}$ became very low. These band changes that occurred in the irradiated SGs to $7.5 \mathrm{dpa}$ were also observed in the LGs when the fluence increased to $1 \times 10^{16} \mathrm{ions} / \mathrm{cm}^{2}(15 \mathrm{dpa})$. With the fluence continuously increasing to $3 \times 10^{16}$ ions $/ \mathrm{cm}^{2}$ ( $45 \mathrm{dpa}$ ), the bands in the SGs and LGs were only slightly shifted to the left, without significant changes. It should be noted that no amorphization was found in the irradiated SGs and LGs under such high fluence.

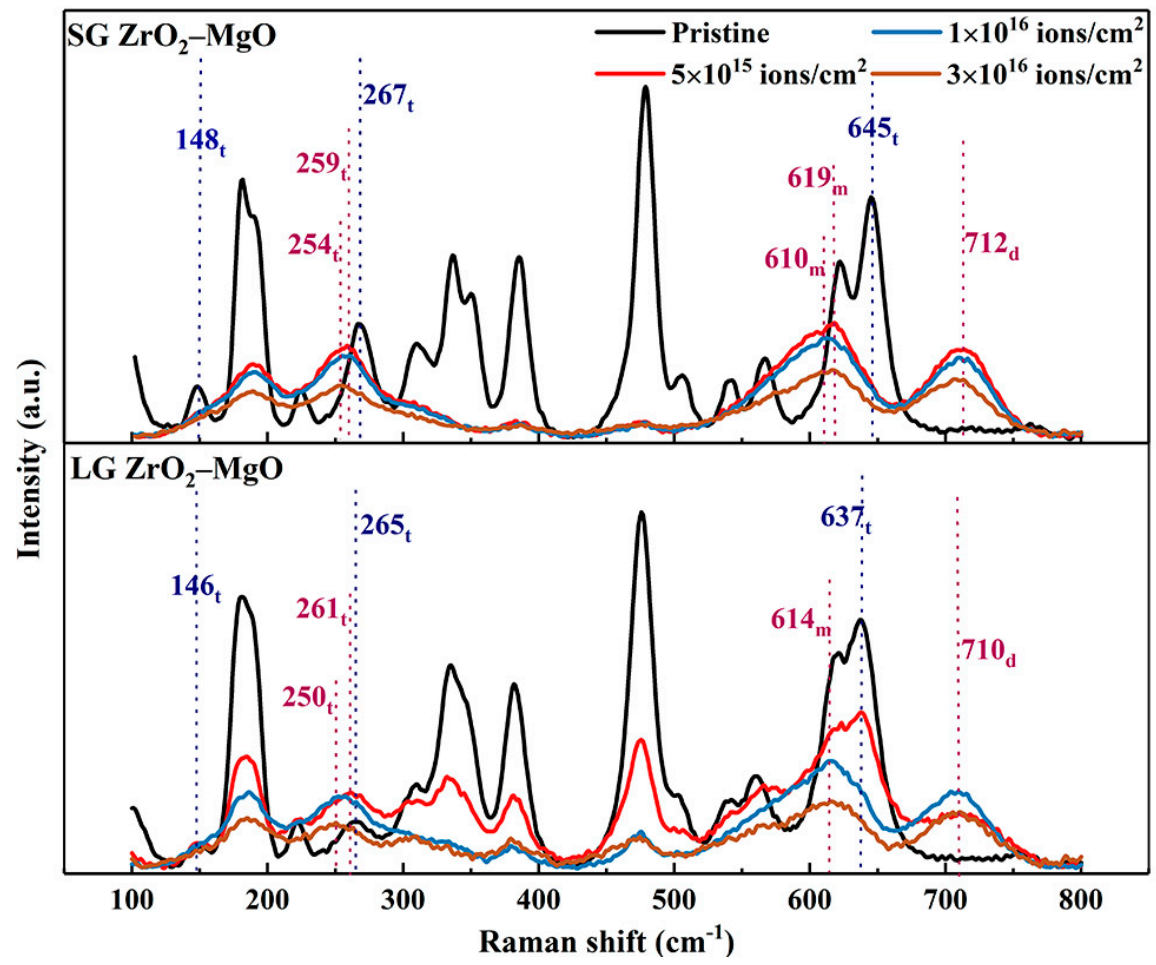

Figure 5. Raman spectra of the pristine SGs and LGs irradiated at RT by $6.4 \mathrm{MeV} \mathrm{Xe}^{23+}$ ions to the fluences of $5 \times 10^{15}, 1 \times 10^{16}$, and $3 \times 10^{16} \mathrm{ions} / \mathrm{cm}^{2}$. The positions of some bands have been marked, and the lower right letters $t, m$, and $d$ represent tetragonal phase, monoclinic phase, and defects, respectively.

For the new bands at 710 and $712 \mathrm{~cm}^{-1}$, they did not represent any vibrational mode of the known $\mathrm{ZrO}_{2}$ phases, but rather revealed the vibrational mode induced by defects in the $\mathrm{ZrO}_{2}$ phases. In addition, there have been two different suggestions made about the bands at between 250 and $261 \mathrm{~cm}^{-1}$. Some researchers have suggested that these vibrational modes were caused by defects [29], while others have suggested that they represent the vibrational modes of the tetragonal phase $[28,30,31]$. Combined with the Raman spectra of the pristine samples, we prefer the second argument, that these bands are obtained from the left offset of the 267 and $265 \mathrm{~cm}^{-1}$ bands with the increase of the fluence, 
respectively. By comparing the four main Raman bands after irradiation, it can be seen that the bands gradually shifted towards the left with increasing fluence, due to the increase in the residual stress and the generation of defects induced by irradiation [28,32]. In addition, the deviation of bands corresponding to tetragonal phase was greater than that of the monoclinic phase, which means that the tetragonal phase was more sensitive to the change of the stress field induced by irradiation than the monoclinic phase [32].

As a whole, with the increase of irradiation damage, most of the monoclinic active modes in the SGs and LGs disappeared, while the relative intensities corresponding to the active modes of tetragonal phase gradually increased, which means that the partial monoclinic phase in the SGs and LGs was transformed into a tetragonal phase. By analyzing the bonds $(\mathrm{Zr}-\mathrm{Zr}, \mathrm{Zr}-\mathrm{O}$, or $\mathrm{O}-\mathrm{O})$ corresponding to each active mode, it was found that the disappeared monoclinic active modes were mainly composed of $\mathrm{O}-\mathrm{O}$ bonds, which indicates that the $\mathrm{O}-\mathrm{O}$ bonds were damaged the most seriously during the $\mathrm{Xe}^{23+}$ ion irradiation [33]. This is consistent with what was described by Simeone et al., that the partial phase transformation was due to the nanometric scale strain field caused by defects in the oxygen sublattice. The strain field can reduce the phase transition temperature and quench the high temperature tetragonal phase [28,34]. Notably, the LGs could withstand higher displacement damage than the SGs in the phase transformation. It is proposed that the presence of low grain size or a high-density grain boundary, and their inherent sub-stoichiometry, may enhance the disorder effect under heavy ion irradiation [35]. The above results show that the ultrafine-grained $\mathrm{ZrO}_{2}-\mathrm{MgO}$ composite ceramic with a large grain size had better radiation tolerance under high energy heavy ion bombardment.

Therefore, it was difficult to directly find out which grain size of composite ceramics had better radiation tolerance performance under ion irradiation with different energy by comparing the results of the above $\mathrm{He}^{+}$and $\mathrm{Xe}^{23+}$ ion irradiation experiments.

\section{Conclusions}

In this work, dual-phase $\mathrm{ZrO}_{2}-\mathrm{MgO}$ composite ceramics with refined grain sizes were prepared by SPS to improve their radiation tolerance performance as IMF. Under $\mathrm{He}^{+}$ion irradiation, the $\mathrm{ZrO}_{2}-\mathrm{MgO}$ composite ceramics had a higher ability to manage He bubbles, relative to the pure $\mathrm{MgO}$ and YSZ. In the composite ceramic, the ribbon-like He bubbles were more likely to be formed in the $\mathrm{ZrO}_{2}$ grains. Meanwhile, the $\mathrm{ZrO}_{2}-\mathrm{MgO}$ composite ceramics with smaller grain sizes had better ability to manage He bubbles than those with large grain sizes. However, under heavy $\mathrm{Xe}^{23+}$ ion irradiation to high displacement damage, the $\mathrm{ZrO}_{2}-\mathrm{MgO}$ composite ceramic with larger grain sizes could withstand higher displacement damage than small grain sizes in the phase transformation. Therefore, it was feasible to enhance the radiation tolerance of the ceramics by grain refinement under low irradiation displacement damage, but not at high displacement damage. For the actual application of $\mathrm{ZrO}_{2}-\mathrm{MgO}$ composite ceramics, the balance between managing He bubbles and phase stability should be considered by choosing a suitable grain size.

Supplementary Materials: The following are available online at http://www.mdpi.com/1996-1944/12/17/2649/s1, Figure S1: Grain orientations of the purchased $\mathrm{ZrO}_{2}(\mathrm{a})$ and $\mathrm{MgO}$ (b) powders, Figure S2: X-ray penetration depth in $\mathrm{ZrO}_{2}-\mathrm{MgO}$ composite versus grazing incidence angle $(\alpha)$ were estimated by geometrically and total external reflection theory, Table S1: The peak He concentration and displacement per atom (dpa) with corresponding ion range of $\mathrm{ZrO}_{2}-\mathrm{MgO}, \mathrm{YSZ}$, and $\mathrm{MgO}$ were calculated by SRIM-2013.

Author Contributions: Conceptualization, W.Q. and F.R.; Validation, M.H., J.T., G.C. and R.Y.; Formal Analysis, W.Q. and M.H.; Investigation, W.Q. and M.H.; Resources, X.R. and B.Y.; Writing-Original Draft Preparation, W.Q.; Writing-Review \& Editing, F.R., Y.W. and W.Q.; Funding Acquisition, F.R., W.Q., C.J. and Y.W.

Funding: We thank the National Science Fund for Excellent Young Scholars (11522543), the Natural Science Foundation of China (11875207, 11475129, 51571153, 11935011 and 11905058), the Natural Science Foundation of Hubei Province, China (2016CFA080), the Scientific and Technological Innovation Projects in Hunan (2018GK2064) and the Fundamental Research Funds for the Central Universities for financial support. Y.Q. Wang acknowledges support from the Center for Integrated Nanotechnologies (CINT), a DOE Office of Science User Facility jointly operated by Los Alamos and Sandia National Laboratories. 
Conflicts of Interest: The authors declare no conflict of interest.

\section{References}

1. Hong, M.; Ren, F.; Zhang, H.; Xiao, X.; Yang, B.; Tian, C.; Fu, D.; Wang, Y.; Jiang, C. Enhanced radiation tolerance in nitride multilayered nanofilms with small period-thicknesses. Appl. Phys. Lett. 2012, 101, 153117. [CrossRef]

2. Yang, T.; Huang, X.; Wang, C.; Zhang, Y.; Xue, J.; Yan, S.; Wang, Y. Enhanced structural stability of nanoporous zirconia under irradiation of He. J. Nucl. Mater. 2012, 427, 225-232. [CrossRef]

3. Zhang, X.; Hattar, K.; Chen, Y.; Shao, L.; Li, J.; Sun, C.; Yu, K.; Li, N.; Taheri, M.L.; Wang, H.; et al. Radiation damage in nanostructured materials. Prog. Mater. Sci. 2018, 96, 217-321. [CrossRef]

4. Beyerlein, I.J.; Caro, A.; Demkowicz, M.J.; Mara, N.A.; Misra, A.; Uberuaga, B.P. Radiation damage tolerant nanomaterials. Mater. Today 2013, 16, 443-449. [CrossRef]

5. Sun, C.; Song, M.; Yu, K.Y.; Chen, Y.; Kirk, M.; Li, M.; Wang, H.; Zhang, X. In situ Evidence of Defect Cluster Absorption by Grain Boundaries in Kr Ion Irradiated Nanocrystalline Ni. Metall. Mater. Trans. A 2013, 44, 1966-1974. [CrossRef]

6. Shen, T.D.; Feng, S.; Tang, M.; Valdez, J.A.; Wang, Y.; Sickafus, K.E. Enhanced radiation tolerance in nanocrystalline MgGa2O4. Appl. Phys. Lett. 2007, 90, 263115. [CrossRef]

7. Bai, X.M.; Voter, A.F.; Hoagland, R.G.; Nastasi, M.; Uberuaga, B.P. Efficient annealing of radiation damage near grain boundaries via interstitial emission. Science 2010, 327, 1631-1634. [CrossRef] [PubMed]

8. Li, X.; Liu, W.; Xu, Y.; Liu, C.S.; Pan, B.C.; Liang, Y.; Fang, Q.F.; Chen, J.-L.; Luo, G.N.; Lu, G.-H.; et al. Radiation resistance of nano-crystalline iron: Coupling of the fundamental segregation process and the annihilation of interstitials and vacancies near the grain boundaries. Acta Mater. 2016, 109, 115-127. [CrossRef]

9. Lu, F.; Wang, J.; Lang, M.; Toulemonde, M.; Namavar, F.; Trautmann, C.; Zhang, J.; Ewing, R.C.; Lian, J. Amorphization of nanocrystalline monoclinic ZrO2 by swift heavy ion irradiation. Phys. Chem. Chem. Phys. 2012, 14, 12295-12300. [CrossRef] [PubMed]

10. Shen, T.D. Radiation tolerance in a nanostructure: Is smaller better? Nucl. Instrum. Methods Phys. Res. Sect. B Beam Interact. Mater. At. 2008, 266, 921-925. [CrossRef]

11. Taylor, M.A.; Alonso, R.E.; Errico, L.A.; López-García, A.; de la Presa, P.; Svane, A.; Christensen, N.E. Structural, electronic, and hyperfine properties of pure and Ta-doped m-ZrO2. Phys. Rev. B 2012, 85, 155202. [CrossRef]

12. Dey, S.; Mardinly, J.; Wang, Y.; Valdez, J.A.; Holesinger, T.G.; Uberuaga, B.P.; Ditto, J.J.; Drazin, J.W.; Castro, R.H. Irradiation-induced grain growth and defect evolution in nanocrystalline zirconia with doped grain boundaries. Phys. Chem. Chem. Phys. 2016, 18, 16921-16929. [CrossRef] [PubMed]

13. Fang, Y.; Ge, W.; Yang, T.; Du, C.; Wang, C.; Liu, S.; Lu, Y.; Yan, Z.; Liu, H.; Liu, F.; et al. Radiation tolerance of La-doped nanocrystalline steel under heavy-ion irradiation at different temperatures. Nanotechnology 2018, 29, 494001. [CrossRef] [PubMed]

14. Ohtaki, K.K.; Patel, M.K.; Crespillo, M.L.; Karandikar, K.K.; Zhang, Y.; Graeve, O.A.; Mecartney, M.L. Improved high temperature radiation damage tolerance in a three-phase ceramic with heterointerfaces. Sci. Rep. 2018, 8, 13993. [CrossRef] [PubMed]

15. Bachiller-Perea, D.; Debelle, A.; Thomé, L.; Behar, M. Damage accumulation in MgO irradiated with MeV Au ions at elevated temperatures. J. Nucl. Mater. 2016, 478, 268-274. [CrossRef]

16. Stoller, R.E.; Toloczko, M.B.; Was, G.S.; Certain, A.G.; Dwaraknath, S.; Garner, F.A. On the use of SRIM for computing radiation damage exposure. Nucl. Instrum. Methods Phys. Res. Sect. B Beam Interact. Mater. At. 2013, 310, 75-80. [CrossRef]

17. Chen, L.; Chang, Y.; Guo, Q.; Zhang, J.; Wan, F.; Long, Y. Phase stability, grain growth and photoluminescence property of nanocrystalline yttria-stabilized zirconia film under $500 \mathrm{keV} \mathrm{Xe6+ion} \mathrm{irradiation.} \mathrm{Nucl.} \mathrm{Instrum.}$ Methods Phys. Res. Sect. B Beam Interact. Mater. At. 2014, 328, 84-88. [CrossRef]

18. Yang, T.; Huang, X.; Gao, Y.; Wang, C.; Zhang, Y.; Xue, J.; Yan, S.; Wang, Y. Damage evolution of yttria-stabilized zirconia induced by He irradiation. J. Nucl. Mater. 2012, 420, 430-436. [CrossRef]

19. Usov, I.O.; Valdez, J.A.; Sickafus, K.E. Temperature dependence of lattice disorder in Ar-irradiated (100), (110) and (111) MgO single crystals. Nucl. Instrum. Methods Phys. Res. Sect. B Beam Interact. Mater. At. 2011, 269, 288-291. [CrossRef] 
20. Dong, L.; Zhang, H.; Amekura, H.; Ren, F.; Chettah, A.; Hong, M.; Qin, W.; Tang, J.; Hu, L.; Wang, H.; et al. Period-thickness dependent responses of $\mathrm{Cu} / \mathrm{W}$ multilayered nanofilms to ions irradiation under different ion energies. J. Nucl. Mater. 2017, 497, 117-127. [CrossRef]

21. Valdez, J.A.; Chi, Z.; Sickafus, K.E. Light ion irradiation-induced phase transformation in the monoclinic polymorph of zirconia. J. Nucl. Mater. 2008, 381, 259-266. [CrossRef]

22. Li, Y.H.; Wang, Y.Q.; Valdez, J.A.; Tang, M.; Sickafus, K.E. Swelling effects in Y2Ti2O7 pyrochlore irradiated with 400keV Ne2+ ions. Nucl. Instrum. Methods Phys. Res. Sect. B Beam Interact. Mater. At. 2012, 274, $182-187$. [CrossRef]

23. Lokesha, H.S.; Nagabhushana, K.R.; Singh, F. Swift heavy ion induced phase transformation and thermoluminescence properties of zirconium oxide. Nucl. Instrum. Methods Phys. Res. Sect. B Beam Interact. Mater. At. 2016, 379 (Suppl. C), 131-135. [CrossRef]

24. Moll, S.; Zhang, Y.; Debelle, A.; Thomé, L.; Crocombette, J.P.; Zihua, Z.; Jagielski, J.; Weber, W.J. Damage processes in $\mathrm{MgO}$ irradiated with medium-energy heavy ions. Acta Mater. 2015, 88, 314-322. [CrossRef]

25. Jiao, L.; Chen, A.; Myers, M.T.; General, M.J.; Shao, L.; Zhang, X.; Wang, H. Enhanced ion irradiation tolerance properties in TiN/MgO nanolayer films. J. Nucl. Mater. 2013, 434, 217-222. [CrossRef]

26. Taylor, C.A.; Patel, M.K.; Aguiar, J.A.; Zhang, Y.; Crespillo, M.L.; Wen, J.; Xue, H.; Wang, Y.; Weber, W.J. Bubble formation and lattice parameter changes resulting from He irradiation of defect-fluorite Gd2Zr2O7. Acta Mater. 2016, 115, 115-122. [CrossRef]

27. Qin, W.J.; Ren, F.; Zhang, J.; Dong, X.N.; Feng, Y.J.; Wang, H.; Tang, J.; Cai, G.X.; Wang, Y.Q.; Jiang, C.Z. Helium retention in krypton ion pre-irradiated nanochannel W film. Nucl. Fusion 2018, 58, 026021. [CrossRef]

28. Miro, S.; Bordas, E.; Thomé, L.; Costantini, J.M.; Leprêtre, F.; Trocellier, P.; Serruys, Y.; Beck, L.; Gosset, D.; Verlet, R.; et al. Monitoring of the microstructure of ion-irradiated nuclear ceramics by in situ Raman spectroscopy. J. Raman Spectrosc. 2016, 47, 476-485. [CrossRef]

29. Verlet, R.; Tupin, M.; Baldacchino, G.; Wolski, K.; Miro, S.; Gosset, D.; Colas, K.; Jublot, M.; Jomard, F. Influence of light ion irradiation of the oxide layer on the oxidation rate of Zircaloy-4. Corros. Sci. 2015, 98, 327-338. [CrossRef]

30. Ciszak, C.; Mermoux, M.; Miro, S.; Gutierrez, G.; Lepretre, F.; Popa, I.; Hanifi, K.; Zacharie-Aubrun, I.; Fayette, L.; Chevalier, S. Micro-Raman analysis of the fuel-cladding interface in a high burnup PWR fuel rod. J. Nucl. Mater. 2017, 495 (Suppl. C), 392-404. [CrossRef]

31. Rawat, M.; Das, A.; Shukla, D.K.; Rajput, P.; Chettah, A.; Phase, D.M.; Ramola, R.C.; Singh, F. Micro-Raman and electronic structure study on kinetics of electronic excitations induced monoclinic-to-tetragonal phase transition in zirconium oxide films. RSC Adv. 2016, 6, 104425-104432. [CrossRef]

32. Kurpaska, L.; Jasinski, J.; Wyszkowska, E.; Nowakowska-Langier, K.; Sitarz, M. Influence of Ar-ion implantation on the structural and mechanical properties of zirconia as studied by Raman spectroscopy and nanoindentation techniques. Spectrochim. Acta Part A Mol. Biomol. Spectrosc. 2018, 195, 184-190. [CrossRef] [PubMed]

33. Kim, B.K.; Hamaguchi, H.O. Mode Assignments of the Raman Spectrum of Monoclinic Zirconia by Isotopic Exchange Technique. Phys. Status Solidi (B) 1997, 203, 557-563. [CrossRef]

34. Simeone, D.; Baldinozzi, G.; Gosset, D.; Le Caër, S. Phase transition of pure zirconia under irradiation: A textbook example. Nucl. Instrum. Methods Phys. Res. Sect. B Beam Interact. Mater. At. 2006, 250, 95-100. [CrossRef]

35. Ciszak, C.; Mermoux, M.; Gutierrez, G.; Leprêtre, F.; Duriez, C.; Popa, I.; Fayette, L.; Chevalier, S. Raman spectra analysis of $\mathrm{ZrO} 2$ thermally grown on Zircaloy substrates irradiated with heavy ion: Effects of oxygen isotopic substitution. J. Raman Spectrosc. 2018, 3, 425-435.

(C) 2019 by the authors. Licensee MDPI, Basel, Switzerland. This article is an open access article distributed under the terms and conditions of the Creative Commons Attribution (CC BY) license (http://creativecommons.org/licenses/by/4.0/). 